\title{
Cartas en/desde Berlín: Morir en Berlín de Carlos Cerda y El desierto de Carlos Franz
}

\section{Letters from/in Berlin: Morir en Berlin by Carlos Cerda and El desierto by Carlos Franz}

Mario Lillo C.

Pontificia Universidad Católica de Chile. Santiago, Chile.

mlillo@uc.cl

\section{RESUMEN}

Cartas escritas en Berlín Occidental y Oriental son el punto de partida del análisis que examina la fuerza ilocutiva y perlocutiva de este tipo textual en Morir en Berlín y El desierto. Además, el artículo discute los problemas de la culpa, del perdón, de la memoria, de la historia narrada/vivida y de algunos intertextos que vinculan a ambas novelas.

Palabras claves: Carta, fuerza ilocutiva/perlocutiva, culpa, perdón, memoria, historia narrada/vivida.

\section{ABSTRACT}

Letters from/in Western and Eastern Berlin are the starting point of this article, in which we examine the illocutionary and perlocutionary strength of this textual type in the novels Morir en Berlin by Carlos Cerda and El desierto by Carlos Franz. Additionally, the article discusses the problems of guilt, forgiveness, memory, told/lived history and some intertexts that link both novels.

Keywords: Letter, illocutionary/perlocutionary strength, guilt, forgiveness, memory, told/ lived history.

Recibido: 03-07-2009. Aceptado: 29-09-2009. 


\section{INTRODUCCIÓN}

T a ciudad de Berlín, en sus dos ya periclitadas versiones Occidental y Orien$\mathcal{L}$ tal, constituye el espacio común de enunciación del discurso epistolar que emana de las protagonistas femeninas de las novelas Morir en Berlin (Cerda, 1993) y El desierto (Franz, 2005). No obstante, el análisis de las respectivas situaciones de enunciación y de los enunciados revela diferencias significativas que se expresan fundamentalmente en aspectos tales como: la actitud de los emisores, los destinatarios, el microespacio de la enunciación, el tiempo de remisión, las motivaciones y las consecuencias que provocan los respectivos textos. Estas diferencias traducen a su vez estrategias divergentes respecto de la memoria conflictiva y de la capacidad que se asigna al lenguaje de elaborar: a) textos con capacidad ilocutiva orientada a la finalidad que persigue el acto de habla que puede constituir la carta: enunciar (afirmar), preguntar, mandar, prometer, etc. (cf. Escandell, 1996: 57 y ss.). Este aspecto concentrará preferentemente nuestra atención a propósito de la carta de Laura a su hija en $E l$ desierto; y b) la posibilidad de elaborar textos con fuerza perlocutiva, vale decir, con la capacidad de generar consecuencias o respuestas físicas, a partir del acto ilocutivo, observables en los pensamientos, sentimientos o acciones de los receptores (cf. ibíd.), como sucede particularmente en el caso de la carta elíptica de Lorena, la protagonista de Morir en Berlín. A modo de aclaración previa señalemos que en este trabajo no estableceremos una distinción conceptual entre la carta y su recreación literaria: la epístola, por lo tanto emplearemos ambos términos indistintamente.

Como una suerte de deslinde previo al análisis, intentemos un breve recuento de las cartas que se escriben en ambas novelas, comenzando por Morir en Berlin:

1. El centro de nuestra atención será la carta que escribe y envía Lorena a las autoridades germanorientales que pueden autorizar su salida del país. Es un documento del cual el lector tan sólo conoce un breve, pero revelador párrafo en la voz del narrador omnisciente. Su contenido es objeto de análisis, esperanza, indignación o desprecio por parte de los respectivos involucrados.

2. En el capítulo VI la novela incluye lo que parece ser una carta de Lorena dirigida a su ex marido. El texto carece de las marcas textuales que permitan identificarla como carta, vale decir encabezado y/o despedida, pero el contexto permite desambiguar el tipo textual. 
3. Cartas de carácter familiar que escribe Lorena a sus padres y de cuyo contenido nos enteramos por la vía del estilo indirecto.

4. Un texto en cursiva denominado Éramos pecadores de autoría del narrador que en el texto desempeña el papel de portavoz de la comunidad. El documento adopta aquel modo narrativo denominado monólogo de la conciencia, su destinatario es el lector, y puede ser evaluado por éste, además de los elementos referenciales, como una especie de carta solicitando comprensión o complicidad.

5. Las únicas cartas directamente transcritas en la novela corresponden a un breve intercambio de mensajes con el objetivo de establecer contacto entre la joven bailarina Leni y su padre. A pesar de su brevedad -tres líneas cada una- poseen todos los rasgos formales que corresponden a este tipo textual.

En El desierto, por el contrario, la correspondencia es prácticamente monódica, pues tan sólo se incluye directamente la carta de Laura a su hija Claudia, documento que está motivado, a su vez, por una carta que la joven escribió a su madre exigiendo una respuesta a la pregunta que sirve de vaso comunicante o hilo conductor a la novela. Se trata de una larga epístola dispuesta y segmentada por el narrador representado en 17 capítulos de longitud más o menos uniforme (los capítulos pares del texto), y que alterna con el relato de este narrador personaje que cumple una función bastante similar a la de aquel de Morir en Berlin: representar a la comunidad, ser su memoria narrativa. En la primera parte de la carta de Laura, ésta hace mención a la de su hija y tan sólo transcribe la pregunta que provoca e impulsa la casi totalidad del acontecer. Cabe además señalar que se trata de una carta con un destinatario específico, pero con una múltiple finalidad en su capacidad ilocutiva, pero que en definitiva no llega a cerrar el circuito comunicativo esperable en este tipo de mensaje, dado que no llega a ser enviada por la destinadora ni leída por la destinataria.

\section{EN BUSCA DEL ESPACIO PERDIDO}

No sólo Lorena, sino los demás personajes protagonistas de ambas novelas dan testimonio del cambio que se ha ido verificando en el viaje "institucional" de los hispanoamericanos a Europa a partir de la Independencia de España a comienzos del siglo XIX. Si en la etapa de formación de las naciones del subcontinente trasladarse al Viejo Mundo era una especie de deber de la nueva elite 
del poder económico, político o intelectual en vías de formación, en los dos siglos de independencia de España que han transcurrido el carácter del desplazamiento experimentó diversas mutaciones. Así por ejemplo, la situación en las décadas que siguieron al proceso de Independencia es descrita en los siguientes términos por Altamirano y Sarlo (1997):

Para los hombres del 37 [la generación de Esteban Echeverría, López o Alberdi en Argentina], el viaje a Europa era un peregrinaje patriótico; lejos de la frivolidad que iba a adquirir en las últimas décadas del siglo XIX, se parece mucho a una exploración cultural y a una educación del espíritu público [...] El viaje es, además, un acto colectivo, porque deberá servir a la nación y desbordar las dimensiones individuales del aprendizaje... (1997: 19).

Dos casos ilustrativos de esa frivolidad a que hacen alusión Altamirano y Sarlo otorgan los protagonistas o personajes secundarios de las novelas Martín Rivas y Los transplantados, ambas del escritor y diplomático chileno Alberto Blest Gana, en las cuales miembros de la clase alta de la época emprenden una especie de peregrinaje social y de retorno a las raíces culturales, e incluso raciales, situadas presuntamente en Francia. A partir del movimiento espiritual y cultural generado por la Ilustración, la Revolución Francesa y el intento de globalización de su tres ideas matrices por parte de aquella especie de multinacional política que fue, o quiso ser, el Imperio napoleónico, esta nación se había convertido en referente cultural de los nuevos estamentos que tomaron el relevo del poder en las naciones en gestación, una vez desplazados manu militari los viejos tercios peninsulares que habían administrado el monopolio económico y cultural ejercido por la Corona española durante más de tres siglos. El viaje de finales del siglo XIX e inicios del siglo XX a Europa es una versión frívola, usando el término de Sarlo y Altamirano, de este movimiento de itinerancia y presunto retorno a las raíces, el cual tendrá como efecto práctico la exportación a este continente, entre otros bienes simbólicos de lo que hoy denominamos la baja cultura, de la estética del tango y de sus representantes más conspicuos y numerosos, aquellos rioplatenses que compitieron con norteamericanos y otros parvenus, métèques y rastaquouères por el escenario bohemio y por el protagonismo en los salones de diversa monta en la capital francesa. Especialmente en la segunda mitad del siglo que recién concluyó en lo cronológico, más precisamente a partir de la década del '70, la nueva versión del viaje "institucional" hacia estas latitudes está troquelada por la desgracia del exilio y, como consecuencia, por el permanente desgarramiento emocional entre el aquí-ahora y el allá-ayer-y-posiblemente-mañana. De este viaje transcontinental dan cuenta 
las dos novelas que examinamos, de las cuales deseamos relevar las cartas como tipos textuales que operan al interior de las novelas en muchos aspectos como vasos comunicantes $\mathrm{y}$, al mismo tiempo, como mecanismos de mise en abyme o cajas chinas de ambas historias narradas por Carlos Cerda y Carlos Franz. Antes de comentar estos textos desde su contenido y relaciones, recordemos brevemente algunas particularidades de la carta como discurso.

\section{CARTAS Y PLURILINGÜISMO}

Desde una perspectiva pragmático-intuitiva, la carta es un tipo de texto, una clase de texto, y desde una perspectiva preteórica la carta puede corresponder a una clase de texto ya sea estético, narrativo, descriptivo, expositivo o protocolario, por mencionar tan sólo algunas de las variantes de mayor incidencia o frecuencia en el uso efectivo de este tipo textual (cf. Lewandowski, 1982: 358). Para algunos de los efectos del análisis que llevaremos a cabo, es preciso recordar, por otra parte, aquella afirmación de Mario Vargas Llosa según el cual la novela es el más imperialista de los géneros "...porque utiliza todos los otros géneros para sus fines y los integra dentro de una síntesis superior" "La novela" 1), y no cabe duda de que la novela encuentra en la carta un vehículo plausible para practicar su imperialismo, su afán hegemónico. Finalmente, desde una perspectiva narratológica la carta como texto equivale al discurso del personaje, es decir, a la manifestación de un discurso de carácter mimético en la novela.

La inclusión de cartas en la novela supondría una reestructuración, una renovación de los géneros literarios y una dialogización de los géneros secundarios, y por lo tanto una debilitación de la composición monológica de la novela tradicional según lo afirmado por Bajtín (cf. 1982:254). Para éste, la carta es una forma de introducción y organización del plurilingüismo en la novela, y como tal instituye algo nuevo que se registra como un género intercalado. Estos géneros o subgéneros que interpola la novela conservan su flexibilidad estructural y su autonomía, así como su especificidad lingüística y estilística. Existe un grupo especial de géneros que juega un papel esencial en la construcción de la novela, y que a veces determina directamente la estructura del conjunto de la novela, creando las variantes especiales del género novelesco. En cierto modo Bajtín "coincide" avant la lettre con Vargas Llosa al sostener que en él están o pueden estar la confesión, el diario íntimo, el diario de viajes, la biografía, la carta. Todos estos géneros o subgéneros no sólo pueden inscribirse en la novela como parte constitutiva fundamental, sino también determinar la forma de ésta como un todo (novela-confesión, novela-diario, novela epistolar, etc.), y 
su aporte enriquecedor consiste en que cada uno de estas variantes tiene sus formas semántico-verbales de asimilación de los diferentes aspectos de la realidad. La novela utiliza precisamente tales géneros como formas elaboradas de asimilación verbal de la realidad (cf. Bajtín, 1989:138).

Asimismo, en esta estructura de mise en abyme se constata la presencia del motivo del espejo como mecanismo que, como sostiene Yuri Lotman, permite eventualmente hacer consciente un código o un "sistema modelizador secundario" que convive como una especie de parásito al interior del código o "sistema modelizador primario" -aunque en este caso no se trata de la lengua natural-y abre la posibilidad de dialogismo en el texto (cf. Lotman, 1982: 17-36). En estos conceptos desarrollados por el crítico de Tartu vemos una correspondencia con aquello que Bajtín denomina géneros secundarios y primarios respectivamente.

Los géneros discursivos son tipos relativamente estables de enunciados elaborados por cada esfera del uso de la lengua, pero del mismo modo existen enunciados separados que tienen una naturaleza individual. El tipo de relación que suscita la coexistencia entre lo individual -asimilable a la parole de Saussure- y lo social al interior de la obra literaria es un problema que aborda Bajtín en "El problema de los géneros discursivos":

Los géneros primarios que forman parte de los géneros complejos se transforman dentro de estos últimos y adquieren un carácter especial: pierden su relación inmediata con la realidad y con los enunciados reales de otros, por ejemplo, las réplicas de un diálogo cotidiano o las cartas dentro de una novela, [destacado nuestro] conservando su forma y su importancia cotidiana tan sólo como partes del contenido de la novela, participan de la realidad tan sólo a través de la totalidad de la novela, es decir, como acontecimiento artístico y no como suceso de la vida cotidiana. La novela en su totalidad es un enunciado, igual que las réplicas de un diálogo cotidiano o una carta particular (todos poseen una naturaleza común), pero, a diferencia de éstas, aquello es un enunciado secundario (complejo) (1982: 248).

Al considerar la función o el lugar de un género primario en uno secundario -digamos, una conversación de carácter cotidiano en un texto ficcional- se puede hacer un símil entre lo individual y lo general representados por una oración que está inmersa en un contexto mayor que la lingüística del texto denomina transfrástico. La oración individual adquiere la plenitud de su sentido únicamente dentro de este contexto, es decir, dentro de la totalidad de un enunciado completo, y lo que puede ser contestado es este enunciado 
completo cuyo elemento significante es la oración (cf. Bajtín, 1982: 272). En otras palabras, la oración adquiere su sentido total dentro de la totalidad del enunciado, vale decir, dentro de las condiciones concretas de la comunicación discursiva (cf. Bajtín, 1982: 273). Además del aspecto cuantitativo involucrado en lo anteriormente señalado, el crítico ruso alude asimismo a la capacidad de representación que se verifica en el interior de la variedad de géneros que conviven eventualmente en un discurso secundario:

La enorme mayoría de los géneros literarios son géneros secundarios y complejos que se conforman a los géneros primarios transformados de las maneras más variadas (réplicas de diálogo, narraciones cotidianas, cartas, diarios, protocolos, etc.). Los géneros secundarios de la comunicación secundaria suelen representar diferentes formas de la comunicación discursiva primaria. De allí que aparezcan todos los personajes convencionales de autores, narradores y destinatarios. Sin embargo, la obra más compleja y de múltiples planos de un género secundario viene a ser en su totalidad, y como totalidad, un enunciado único que posee un autor real (Bajtín, 1982: 289).

De este modo, la inclusión de géneros primarios en secundarios no resulta necesariamente en una mutación en el carácter ontológico del género primario de que se trate, dado que no se produce un cambio real de los sujetos discursivos. Se entiende que esto es válido en la medida en que el lector entra en el pacto de verosimilitud que ofrece el autor empírico en el sentido de que consideremos como "real" la posible polifonía existente al interior del texto, y esta es precisamente la invitación que se nos extiende en las dos novelas que analizamos. En consecuencia, las relaciones que se establecen entre los géneros primarios reproducidos, a pesar de ubicarse estos dentro de los límites de un solo enunciado, no se someten a la gramaticalización y conservan su naturaleza específica, la cual es fundamentalmente distinta de la naturaleza de las relaciones que existen entre palabras y oraciones en el enunciado (cf. Bajtín, 1982: 262). Así, se puede sostener con Bajtín que, en general,

[L]os géneros intercalados en la novela, tanto pueden ser directamente intencionales como completamente objetuales, es decir, carentes por completo de las intenciones del autor - no se trata de una palabra pronunciada, sino solamente mostrada como cosa-; pero, con más frecuencia, refractan, en una $\mathrm{u}$ otra medida, las intenciones del autor, al mismo tiempo que algunos de sus elementos pueden situarse de manera diferente ante la última instancia semántica de la obra (1989: 139). 
No obstante, en lo que sigue haremos abstracción de la capacidad irradiadora de la carta como género intercalado, o de la eventual mutación ontológica de ambas novelas por efecto de la inclusión de este tipo de texto parásito, para concentrarnos en su versatilidad ilocutiva como enunciación y en los enunciados que finalmente adquieren una fuerza perlocutiva divergente en los dos textos y los transforman en instancias de poder.

\section{PERDÓN Y CULPA}

En referencia a la dimensión discursivo-pragmática de la carta como discurso intercalado, en Morir en Berlín el documento principal que motiva este análisis es la carta de petición de visa de Lorena. Se trata de un texto mediante el cual el emisor se proyecta a un futuro, mientras la novela El desierto incluye implícita y explícitamente las dos cartas que demandan explicación y petición de perdón respectivamente, como se anotó más arriba, y que remiten exclusivamente al pasado. Así, la breve y elíptica carta de Claudia a su madre contiene, más allá de lo estrictamente formal que podemos suponer, una sola frase que condensa y reclama una explicación. La respuesta de Laura, la madre, tiene la complejidad de erigirse simultáneamente en explicación, justificación y petición de perdón. Examinadas en su función comunicativa, las cartas de ambas novelas son textos que intentan persuadir y argumentar como reflejos del dolor, de la esperanza, de la justificación, pero también de la rabia, la frustración y, especialmente en el caso de El desierto, de una memoria exhaustiva y largamente reprimida del pasado. Empleando otra terminología, en ambas cartas predomina la función apelativa o conativa del lenguaje toda vez que sus respectivas destinadoras, Lorena y Laura, buscan alcanzar un efecto concreto acudiendo implícitamente al poder de la escritura, vale decir, recurriendo a su capacidad ilocutiva y perlocutiva. Más adelante intentaremos determinar hasta qué punto ambas logran sus objetivos.

Un vaso comunicante de especial relevancia que permite vincular ambas novelas es el motivo del perdón inscrito en algunas de las cartas a las cuales, como lectores, tenemos acceso directo o indirecto. Aquella de Lorena en $\mathrm{Mo}$ rir en Berlín, que será objeto de análisis preponderante en este trabajo, en la lógica del relato está dotada de un estatuto doble: por una parte constituye un verdadero cráter activo en la novela, es decir, adquiere la categoría de función cardinal -en la terminología de Barthes- que condensa e induce el movimiento centrífugo y centrípeto del acontecer, puesto que genera una serie de conflictos, modificaciones y consecuencias en el estado de ánimo y en la praxis cotidiana, tanto en el ámbito doméstico de la comunidad de exiliados cuanto en ciertas 
esferas gubernamentales, afectando incluso las dinámicas o los destinos individuales de algunos integrantes de la nomenklatura del país anfitrión, como es el caso del Ministro del Interior, o el de Mario, ex esposo de Lorena, y su nueva pareja, hija del Ministro; por otra parte, la carta de esta chilenische Patriotin es un trámite y requisito para solicitar una especie de indulgencia, o más bien autorización, del Padre local encarnado en La Oficina, ente que, en la perspectiva del narrador, está investido de la calidad de sucedáneo in parvo del terrible Padre castigador que se ha enseñoreado en la lejana patria. En otras palabras, el documento redactado por Lorena es signo de la voluntad (más bien de la necesidad) de someterse a aquello que, para el contexto chileno post 1973, Eugenia Brito denomina "la ley del Padre" (cf. 1994: 43), y que en los casos chileno y germanooriental tan sólo se diferencia en el adjetivo calificativo -fascista y marxista respectivamente- pero que opera desde una lógica coercitiva y represiva común. A su vez, en El desierto el perdón -aquí sí es fundado hablar de perdón- es solicitado a la hija que espera la respuesta a la pregunta por la responsabilidad de la madre en los luctuosos hechos acaecidos en el Chile de los primeros tiempos del Golpe, en su calidad de cauteladora oficial del Estado de Derecho. Pero además el otorgamiento del perdón tiene como requerimiento la existencia real o virtual de un tribunal que juzga y condena o exonera. La carta de Laura como texto que solicita y justifica al emisor induce a la tentación de explorar una lectura intertextual que nos podría conducir, por ejemplo, a Kafka, quien en su Carta al Padre se justifica, pero al mismo tiempo emplaza y juzga al Padre castigador, sin embargo el posible vínculo entre ambos textos nos aleja de nuestro objetivo. En la novela de Cerda, La Oficina es el tribunal supremo colegiado y aparentemente impersonal; en la novela de Franz (¿Kafka?) el tribunal es unipersonal, pero especialmente riguroso dada la nula relación directa de Claudia, la autodesignada jueza de su madre, con los hechos sometidos al escrutinio de la memoria.

Examinemos, en segundo lugar, un motivo complementario para el perdón en el contexto de El desierto, el de la culpa, especialmente en el caso de Laura. Este motivo se expresa ya en el primer segmento de la carta de la jueza Laura Larco a su hija Claudia en el capítulo dos de la novela: "Confirmé en el oficial de caballería la oscura premonición que me asediaba, y comencé a saber de qué me había venido sintiendo, desde el día mismo del golpe, culpable" (2005: 30); y continúa en el segundo segmento de la larga carta que corresponde al capítulo 4: "Mi transacción legalista, mi sueño privado de hacer justicia con leyes injustas, similar al del presidente suicida, desembocaba en el miedo y la culpabilidad" (49). A partir de la manifestación de este sentimiento que actúa prolépticamente, y que funciona como lo que Vargas Llosa denomina "dato 
escondido en hipérbaton", pues la cifra del estigma que grava la existencia de Laura es revelada en las postrimerías del relato, la culpa se disemina en el texto anafóricamente, y en el curso de la narración se traslada lentamente y con diversos matices a las autoridades del presente y del pasado de Pampa Hundida, y a la propia Laura de la infancia y adolescencia. En efecto, ella abandonó a su padre sufriente y melancólico que había sido, a su vez, abandonado por la madre de Laura en un contexto narrativo cuyo enunciado dialoga con el cuento "El infierno tan temido" de Juan Carlos Onetti. En este cuento, un melancólico Risso se casa con Gracia César, joven actriz 20 años menor e intérprete de la dramaturgia de Ibsen -de Casa de muñecas, para mayores señas y coincidencias con el relato de Franz. Además, ya hacia el final de su carta Laura reconoce en el capítulo 30 su responsabilidad fundamental en lo sucedido en el pueblo, la futilidad de la escritura y la mendacidad del texto epistolar que ha intentado reemplazar a la vivencia del horror del pasado. Así lo confiesa a Claudia: "Tu rebeldía, tu viaje hacia los orígenes, tu carta llena de preguntas sin responder, me acusan. En lugar de quitarle la venda a esa otra que descubrí en mí, a mi prisionera, le inventé una máscara de papel, de miles de páginas y razones" (379). Por cierto, la máscara de papel no solo está formada por la carta, sino también por las páginas de su obra Moira, un tratado acerca de Filosofía del Derecho, disciplina a la cual ha dedicado los últimos 20 años de su vida en un intento por sustituir, por deslindar el texto de la vida. Es por ello que un par de líneas más adelante Laura agrega: "Tú decidiste tomar el camino que yo abandoné, tratar de hacer justicia en lugar de pensar en ella” (Ibíd.).

Distinto y tal vez más complejo es el caso de la culpa en Morir en Berlín, pues en esta novela el sentimiento no se concentra exclusivamente en la protagonista para diseminarse paulatinamente entre el resto de la comunidad de exiliados, a quienes el narrador colectivo se refiere como virtuales integrantes de un ghetto. En las reflexiones de su texto El problema de la culpa (1998), las cuales están hondamente traspasadas por el dolor de la Segunda Guerra Mundial recién concluida, Karl Jaspers distingue cuatro tipos de culpa: a) la criminal cuya Instancia es el tribunal de justicia respectivo; b) la política, cuya Instancia es la fuerza y la voluntad del vencedor (recordemos el contexto de los juicios de Nürnberg en que apareció por primera vez la reflexión de Jaspers); c) la moral, según la cual "[S]iempre que realizo acciones como individuo tengo [...] responsabilidad moral, la tengo [...] por todas las acciones que llevo a cabo, incluidas las políticas y militares. [...] Toda acción se encuentra sometida también al enjuiciamiento moral. La instancia es entonces la propia conciencia..." (1998: 53); y d) la culpa metafísica, cuya Instancia es Dios (cf. 1998: 53-4). Esta última es definida por Jaspers en los siguientes términos: "Hay una solida- 
ridad entre hombres como tales que hace a cada uno responsable de todo el agravio y de toda la injusticia del mundo especialmente de los crímenes que suceden en su presencia o con su conocimiento. Si no hago lo que puedo para impedirlos, soy también culpable [...] de un modo que no es adecuadamente comprensible por la vía política o moral” (54). ¿A cuál de las posibilidades anteriores responde el sentimiento que despliega la protagonista de Morir en Berlín en su carta? Diríase que a una combinación entre la culpa moral y la metafísica, veamos: En esta etapa de su residencia en Alemania Oriental tras 10 años de exilio, Lorena permanece al margen de todo asomo de culpa colectiva, pues ya ha superado la instancia del duelo y de diálogo con su conciencia. Por lo demás, su grado de compromiso político con el proceso de cambios en Chile no alcanzaba la intensidad del de su marido, y por ello vive el exilio con una lógica más centrada en las vicisitudes de lo cotidiano y de la sociabilidad propia de la mujer latinoamericana, en esa época por lo general más interesada en su casa que en el mundo -parafraseando a un Goethe hoy políticamente incorrecto-, aun cuando la ex actriz se desempeña como lectora de literatura latinoamericana en una editorial del Estado. Son los demás integrantes del ghetto quienes viven en un ambiente enrarecido por la sensación moral y metafísicamente culposa: "Ser enfermo mental es vivir en un universo de culpabilidad, un universo kafkiano de culpabilidad difusa o confusa", señala Jean Lacroix (1980: 26). Esta sensación les ha sido inoculada por la Dirección local del Partido, y consiste en no haber sido capaces de padecer lo suficiente después del Golpe de Estado de 1973 como para poder obtener ahora la redención del pecado original que radica en haber optado por el exilio y no por el martirologio, como muchos camaradas torturados o muertos en la lejana patria. Se trata de una sensación que hace pensar en una mutación experimentada por sus protagonistas que los ha llevado, sin solución de continuidad, desde el "proceso" allendista al "proceso" kafkiano. Dadas las circunstancias, en estos exiliados se constata lo que sostiene Lacroix acerca de la culpa: "El sentimiento de culpabilidad tiene en consecuencia un doble origen: la angustia ante la autoridad y -posterior a ésta- la angustia ante el super yo" (1980: 19), en donde el super yo es claramente identificable con esa doble Instancia -en palabras de Jaspers- formada por la dirigencia chilena y la germanooriental del Partido. Para Lacroix, la angustia ante la autoridad constriñe al individuo a renunciar a sus pulsiones señalándole límites estrechos para maniobrar; en tanto la angustia ante el super yo lo empuja a castigarse (cf. 1980: 19-20). No es cuestión, sin embargo, de que los integrantes del grupo de huéspedes del Primer Estado de Obreros y Campesinos en Suelo Alemán, como ironiza constantemente el narrador colectivo, estén enfermos de culpa como aquel Josef K. de El proceso, pero resulta evidente que, 
atendiendo a las expectativas de los funcionarios de La Oficina, sería un gesto de consecuencia revolucionaria confesar la ignominia de haber solicitado asilo, razón por la cual a los ojos de los comisarios encargados de Control y Cuadros del Partido los exiliados llegaron al país anfitrión con la marca de Caín: la culpa metafísica de haber pecado de falta de solidaridad, la culpa moral por las acciones, o más bien omisiones, perpetradas. Así queda de manifiesto en la especie de carta al lector que expone el narrador en las páginas 30-2, y que lleva por título: "Éramos pecadores". Puede llamar la atención el empleo de un lexema tan contaminado de religiosidad como el del título en el contexto del relato de Cerda, no obstante Lacroix hace la siguiente distinción que aclara este problema: "La culpabilidad moral, propiamente dicha, no se refiere al 'pecado', sino a la 'falta', y concierne a la humanidad entera, religiosa o no" (1980: 56). Tras superar la primera etapa del exilio marcada sicológicamente por el trauma, el duelo y el sentimiento de culpa por la pérdida de los referentes familiares y sociales en el país de origen, después de nueve años Lorena se ve enfrentada a un segundo duelo y a una segunda culpa por la pérdida de su marido. En este momento, ella se encuentra en la tercera etapa del exilio, la del desmoronamiento de los mitos, de las utopías de carácter político y social formuladas ante todo discursivamente por el proyecto socialista de la Unidad Popular. Y decimos "discursivamente" al recordar lo que aclara Lorena a Frau Gerlach, su compañera de trabajo en la Editorial, acerca de que en Chile " $[\mathrm{N}]$ o tuvimos un solo día de socialismo..." (53), y lo que sostiene Moulián acerca de la ilusión retórica, del sueño romántico de "profetas desarmados" que fue el experimento liderado por Allende (1997: 160). No obstante que ella siente que no forma parte de la culpa colectiva que pesa en el ambiente del ghetto, Lorena sí siente culpa por haber seguido a su marido al exilio y por haber sido abandonada por éste, quien se marchó del hogar tras Eva, una auténtica hija del país anfitrión. Ella siente además culpa por abandonar a sus hijos al sumergirse en el dolor de la pérdida, por mentir a sus padres acerca de su vida en Berlín y por haber tenido una brevísima aventura en una noche de celebración. Por su parte, sus padres sienten culpa por haber perdido sus ahorros en una inversión fracasada en el contexto de la debacle económica de inicios de los años ' 80 en Chile, así como Mario siente culpa por haber abandonado a Lorena y por abandonar a Eva en las noches para ser parte de la comedia del matrimonio normal a la llegada a Berlín Oriental de los padres de Lorena quienes, por su parte, mienten acerca de su situación precaria por la bancarrota. Culpa es lo que siente el Senador por utilizar los privilegios de su rango en el apparatchick para tramitar una visa en el Consulado chileno en Berlín Occidental con el objeto de poder viajar a morir en la patria; como también se siente culpable de su atracción por 
Leni, la joven vecina en busca de un redentor que la libere de su condición de rehén, como lo señala visiblemente el intertexto de "El holandés errante" en la novela. Y la joven bailarina a su vez está pagando una culpa ajena, la de ser hija de un desertor que huyó a Alemania Occidental hace muchos años. Ante la dimensión de las culpas, ¿existe en la novela de Cerda un modo de exorcizarlas como intenta hacer Laura en $E l$ desierto mediante la escritura? No, no lo hay, acaso porque esta comunidad de culpables ha delegado, sin saberlo, la narración de ese sentimiento en un amanuense: el narrador oculto tras la primera persona plural, cuya estrategia parece ser más bien el ocultamiento que la develación; la protesta y el lamento en sordina antes que la confrontación abierta con quienes deciden sobre sus destinos. Así entonces, perdón y culpa funcionan como ideologemas que recubren con menor o mayor intensidad ambas novelas, posibilitando un vínculo entre el texto y el mundo respectivo a que remiten los enunciados.

\section{OTRAS INTERTEXTUALIDADES}

La carta de petición en Berlín Oriental es emitida por Lorena, un destinador en situación de inferioridad jerárquica respecto del destinatario, y no obstante su actitud es de superioridad moral, lo cual prácticamente transforma la supuesta petición en una exigencia. La carta de Laura en Berlín Occidental es emitida desde una situación de superioridad familiar propia de la relación madre-hija, al menos en la cultura latinoamericana, pero desde un nuevo estatuto moral que queda fijado desde el momento en que Claudia formula su pregunta: ¿dónde estabas tú mamá, cuando todas esas cosas horribles sucedieron en tu ciudad? Esta pregunta, sabemos, es la que a su vez el tribunal de la opinión pública internacional, el tribunal de la Historia o, como sostiene Laura en su carta, “... los cuchillos de la Historia” (2005: 31), hizo al pueblo alemán después de la Segunda Guerra Mundial respecto de Auschwitz, Sachsenhausen, Dachau, etc. Recordemos que es precisamente la visita que realiza Claudia a Sachsenhausen tras la caída del Muro la primera incitación que la conduce posteriormente a plantear la interrogante a su madre respecto a su responsabilidad como jueza y como persona en las violaciones a los derechos humanos posteriores a septiembre de 1973 en Chile. En este período Laura fue testigo "privilegiado" de la instalación de un campo de concentración en Pampa Hundida, Ministro de Fe de la farsa legal que sancionaba esas violaciones y, finalmente, víctima ella misma. También mencionemos la singular intertextualidad que emerge de la historia narrada por Laura a propósito de esta visita de Claudia a Sachsenhausen. Dice 
Laura en su carta dirigiéndose a su hija: "Sólo pude recordarte el momento aquel cuando Primo Levi, en su memoria de Auschwitz, intenta tomar una estalactita de hielo para saciar su sed abrasadora y un guardia se lo impide. Por qué, pregunta él, y el guardia -filósofo natural del horror, a su modo- le contesta: Hier ist kein Warum! Aquí no hay un porqué" (49). Sin tener conciencia de ello, el anónimo guardia retoma e invierte trágica e inconscientemente aquella expresión acuñada tres siglos antes por el místico y poeta lírico barroco Angelus Silesius que parece condensar su principio estético: "Die Ros' ist ohne Warum..." -La rosa es sin porqué- (1949: 1. Buch 289: 39), expresión que, a su vez, reformula el poeta creacionista Vicente Huidobro en "Arte Poética": "Por qué cantáis la rosa, ¡oh Poetas/hacedla florecer en el poema" (1976: I: 219). De este modo, la pregunta por la esencia de la belleza frágil entra en diálogo con la respuesta que no quiere o no puede explicar el horror, y entonces se produce una extraña simbiosis en la cual belleza y horror devienen inefables, pues no dan cabida a una filosofía que pregunta los por qué de la existencia. No obstante, en su carta Laura no se detiene en consideraciones filosófico-estéticas, pues su discurso epistolar está enderezado a explicar, a explicarse y, en la medida de lo posible, frente al tribunal filial de hoy a justificar sus acciones como Jueza en Pampa Hundida 20 años atrás.

Vale además la pena destacar una vez más la disonancia que se detecta en la actitud de las cartas de Lorena según sean los destinatarios, entre los cuales media una enorme diferencia en el poder que detentan respecto de la emisora. Si, como decíamos, al escribir un texto epistolar de petición de visa a una autoridad como La Oficina que tiene poder casi absoluto sobre su destino, Lorena emplea un tono belicoso, reivindicativo y provocativo, no llama la atención que tratándose de personas como sus padres, con quienes se puede suponer una relación de poder de carácter más horizontal, la mujer emplee un tono obviamente familiar, pero contaminado por la mentira de los lugares comunes acerca de la vida cotidiana familiar.

Finalmente, y a propósito de los vasos comunicantes entre ambas novelas, el Senador asocia el blanco de la nieve de Berlín (1993: 103) con la pampa salitrera, el mismo paisaje de Pampa Hundida en El desierto donde domina el blanco de la pampa asociado con la muerte. Según el relato del Senador a Leni, el desierto, el laberinto perfecto para Borges, se traga a los hombres que sobreviven explotados en las faenas salitreras. La paradoja, no obstante, es que el salitre se asocia a su vez con la vida, con el crecimiento y la fertilidad, una fertilidad que en el caso de Laura significará un recuerdo permanente del horror y una represión constante de los recuerdos de la experiencia vivida con Mariano Cáceres Latorre, el militar a cargo del campo de prisioneros en Pampa Hundida. 


\section{TEXTO Y VIDA: NARRAR Y VIVIR LA HISTORIA}

La pregunta que hace Claudia en su carta tiene la virtud de desplazar los límites de la supuesta superioridad moral de la madre y Jueza y restringir el espacio de maniobra en el cual ha estado operando desde el inicio del exilio en Berlín. Para recuperar los márgenes originales, Laura debe entonces confrontar el pasado mediante el ejercicio de la memoria que refleja la larga carta que escribe a Claudia, intentando dar respuesta a la inquisición de ésta. Se trata de un ejercicio que se extenderá hasta el momento en que tome conciencia de que, como sostiene Derrida en La diseminación, la escritura es una especie de fármacon que actúa sobre la memoria hipnotizándola, fascinándola, adormeciéndola y haciéndola salirse de sí en el monumento (cf. 1975: 157-8). Por favorecer la escritura el descuido de la memoria efectiva -Proust diría la memoria involuntaria- es que Laura decide finalmente transformar su historia narrada en una historia vivida y recuperada en el escenario real de la experiencia. Consecuentemente, decide viajar a Pampa Hundida a exorcizar los fantasmas de ese pasado ominoso y a complementar lo narrado con lo por vivir y recobrar. En este sentido, el viaje de Laura a Pampa Hundida no hace sino reflejar el desajuste entre texto y vida, entre lo que en el ámbito narratológico Paul Ricoeur denomina tiempo narrado y tiempo vivido (cf. 1996: II: 469 y ss.; III: 942). Efectivamente, en Morir en Berlín la carta de Lorena es una suerte de historia dicha que aspira a transformarse en una historia vivida que, como tal, se proyecta al futuro y no tiene nostalgias pendientes con el pasado remoto, como es el caso de Laura; pero en El desierto el proceso es más complejo por tratarse de una historia vivida en el pasado lejano que intenta dar cuenta de sí como historia dicha o narrada, produciéndose entonces el mencionado desajuste en virtud de la insuficiencia del lenguaje, de la escritura, para reivindicar la experiencia traumática. Por ello, en Laura la memoria funciona como representancia (Vertretung) de la experiencia concreta, pero en ningún caso como nostalgia sustitutiva.

Mientras Laura no logre completar las tres etapas del trabajo de duelo que postula Freud -recordar, repetir, elaborar (erinnern, wiederholen, durcharbeiten) - seguirá inmersa en la melancolía transfigurada en texto, en mera escritura-fármacon, palabra esta que, como se sabe, también significa veneno. En virtud de lo anterior, la historia de Laura constituye una cadena formada por tres momentos que se inician con lo vivido, continúan con lo narrado para finalmente avanzar hacia el último eslabón: lo por vivir o porvenir. En este sintagma, el eje o núcleo central es la carta a Claudia, pues en ella confluyen el pasado, el presente y el futuro: lo vivido, lo que se dice y lo indecible que debe ser confrontado y (re)vivido. Por lo tanto, la carta-fármacon de la memoria se 
transforma en vivencia y en ajuste de cuentas con el pasado y con la historia personal puesta por muchos años entre paréntesis, en un tour de force que en Laura ha transmutado la praxis de la aplicación de la justicia en asepsia teórica. Por lo demás, en ambas novelas la escritura epistolar opera como un mecanismo de inversión del poder, y en el caso de Lorena es tanto así que, a pesar del escándalo que produce en la comunidad de exiliados y en las esferas del poder el tono (Der Ton macht die Musik) de su carta-petición de visas para ella y sus hijos, ella logra su objetivo de una manera que en otras circunstancias habría significado una deshonra, una mácula para su condición de exiliada: ella es desterrada del paraíso socialista que la había acogido con fraternal solidaridad. Luego de su expulsión, Lorena visitará a sus hijos semanalmente desde su nueva casa en el territorio del enemigo ideológico: Berlín Occidental.

Consciente o inconscientemente, ambas cartas se plantean como una suerte de salvoconducto que permitirá a las dos destinadoras retornar a las profesiones que debieron abandonar por la fuerza de las circunstancias: Lorena tiene la posibilidad de reintegrarse a la actividad teatral en México gracias a la invitación de su amiga Patricia. Laura consigue retomar su puesto de Jueza de Pampa Hundida por el hecho de que, con el retorno de la democracia a Chile, Benigno Velasco, su antiguo profesor de la Escuela de Derecho, ha sido nombrado Ministro de Justicia. Pero por otra parte resulta notorio el contraste que evidencia la situación de ambas mujeres respecto del "fantasma de la libertad", como diría Luis Buñuel, pues como se desprende de su carta a La Oficina la protagonista de la novela de Cerda es prisionera de su presente en Berlín Oriental, pues al momento de redacción de la carta-petición aún es rehén de su amor por Mario, pero libre respecto del futuro y del pasado -digamos- institucional, aludiendo al terreno político. Esta situación se evidencia en esa suerte de reconvención que hace Lorena a su ex esposo en un formato ambiguo que adopta una retórica epistolar, vale decir, aquel tipo de diálogo aplazado (cf. Riera, 1996: 287) que corresponde a toda carta, pero que al mismo tiempo parece un soliloquio o monólogo de la conciencia con destinatario obvio. Del otro lado del muro, Laura experimenta la libertad del presente, pero la carta es testimonio de su estado de parálisis respecto de su pasado. Por tal motivo, su futuro depende de la superación de la melancolía presente y no asumida hasta el momento de la escritura, y de exorcizar los fantasmas del pasado que la rondan; el futuro de Lorena, por el contrario, depende de la liberación de su presente de dependencia material y emocional. En relación con la actitud de ambas protagonistas frente al tiempo, y si seguimos lo expuesto por Lacroix en su texto ya citado, en los dos casos se puede argüir una especie de arrepentimiento, pues éste “...salva de la desesperación 
dando una tarea que cumplir. Ya no se trata de un lamento vano [como en el remordimiento], sino de un acto que transforma lo que ha sido y al que acompaña la esperanza” (60). Visto así, es claro que el arrepentimiento es más evidente en el caso de Lorena, en especial por el factor de esperanza que supone su reinserción en la actividad teatral, y no así tanto para Laura, quien viaja de regreso a Pampa Hundida con el dilema de ignorar el resultado de su confrontación directa con su pasado y con su hija. Dada su actitud en Berlín, puede ser que en los 20 años transcurridos en esta ciudad en ella haya prevalecido, más que el arrepentimiento, el remordimiento, el cual para Lacroix “... mira hacia el pasado [en tanto], el arrepentimiento contempla el porvenir" (60). La vida emocionalmente estéril de la ex jueza tal vez encuentre su fundamento en el mudo ejercicio del remordimiento, ese lamento de naturaleza ética que es inútil, ineficaz como lamento (cf. Lacroix, 1980: 60).

\section{MODALIDADES DISCURSIVAS Y PUNTO DE VISTA}

Una de las divergencias formales claramente detectables en las cartas de las protagonistas de ambas novelas es su presencia o ausencia concreta: si en el caso de Laura se trata de un discurso manifiesto y entregado de modo (aparentemente) directo al lector, sin instancias narrativas que lo mediaticen, y obviando el hecho de que la alternancia de capítulos dedicados a las cartas con capítulos reservados al narrador colectivo es producto de una voluntad editora, el de Lorena es un discurso que llega al lector de manera elíptica o aproximativa, ya sea por la vía del estilo indirecto empleado por el narrador personaje, mediante los argumentos conciliatorios de Mario o los indignados comentarios del Senador, quien como integrante del Comité respectivo del Partido debe decidir acerca de la materia de la carta. En este contexto, es pertinente especular si acaso estas modalidades narrativas adoptadas por los respectivos hablantes reproducen a su vez las condiciones explícitas e implícitas de producción textual que rigieron ambos espacios materiales de enunciación en el tiempo de la aventura: en uno, la libertad de opinión y palabra y la libre circulación de las ideas; en el otro la censura, el discurso elíptico o soterrado, lo sabido por vía indirecta que en el texto se traduce precisamente en el recurso al estilo indirecto utilizado por el narrador-testigo-amanuense de la comunidad de exiliados chilenos en Alemania Oriental. A pesar de su diferente modo de materialización en las respectivas novelas, ambas cartas responden al procedimiento de mise en abyme, si bien, como anotáramos, en el caso de la carta de Lorena es el narrador intradiegético colectivo quien asu- 
me la trasmisión del contenido al lector. Dada la perspectiva comprensiva de éste y las consecuencias específicas de la carta, el lector empírico debe hacer fe de que lo relatado no es mera especulación, sino corresponde a conocimiento confiable acerca de los entresijos del mundo de los exiliados. En efecto, y como observación lateral, vale la pena hacer notar la muda permanente y sin marcadores explícitos en el punto de vista de la novela, desde el momento en que este narrador anónimo -pero representante de la comunidad, y que en cierto modo recuerda a ese misterioso "nous" del primer capítulo de Madame Bovary o al narrador de A Rose for Miss Emily de Faulkner- alterna con el clásico narrador omnisciente. Así, a poco andar el relato este último narrador nos hace participar de las intimidades más recónditas de la conciencia de los personajes protagonistas, sean estos Lorena, el Senador o Eva; o bien es testigo de conversaciones privadas de Leni y su padre, o de Mario y Eva, sin diferenciarse de manera clara del estatuto narrativo del narrador-miembro de la comunidad de exiliados. En otras palabras, desde el inicio de la novela el narrador-testigo quien, por definición, debería mostrar un conocimiento limitado o selectivo del universo diegético, se funde imperceptiblemente con el narrador omnisciente, y al proceder de esta manera se relativiza la posibilidad de establecer una narración polifónica stricto sensu, puesto que esta muda oficiosa y solapada del narrador convierte a las distintas voces en réplicas de la voluntad narrativa de esta voz indiscreta, limitando así la "... dialogización de los géneros secundarios...”, y favoreciendo entonces la monofonía en la novela. En Morir en Berlín se produce entonces aquella (malograda) posibilidad de dialogismo que Bajtín atribuye a la carta inserta en otros textos, como citáramos más arriba (cf. M.M. Bajtín 1982: 254). Lo mismo -la carta como réplica de una voluntad narrativa que se enmascara de polifónica- sucede con la carta a La Oficina y, por cierto, con las cartas que Lorena intercambia con sus padres, en las cuales el enunciado está caracterizado por la impostación y la mendacidad en relación con su realidad matrimonial y familiar, como señaláramos más arriba. Respecto de El desierto, si bien el texto epistolar es presentado directamente al lector, no obstante la polifonía también es limitada, pues por una parte en la novela sólo se hace explícita la carta de Laura a Claudia, y sólo a través de la madre se conoce el breve contenido de la de la muchacha. En este caso, y similarmente a lo que sucede en Morir en Berlín, el lector debe hacer fe de la palabra de la ex jueza; y por otra parte el final del texto revela a Mario como narrador-editor de todo el material que hasta ese momento creíamos proveniente de Laura, con lo cual también en esta novela el plurilingüismo aparece como simulacro o como componente del pacto de verosimilitud con el lector. 


\section{COMENTARIO FINAL}

Acaso si lo más trascendental de la conclusión que se puede obtener al cotejar las cartas examinadas anteriormente sea la constatación acerca de la distinta capacidad performativa que adquieren ambas cartas, o las palabras en general, para producir una realidad determinada. Más allá del concepto tradicional de representación que implica traer a la presencia del sujeto una realidad que existe previamente, el enunciado performativo que emana de las respectivas cartas se transforma en diversamente operante frente a situaciones que no existían con anterioridad al discurso, y por ello estos enunciados incluso nos sitúan ante realidades que se convierten finalmente en creadas a partir de la acción de la imagen o de la palabra. Para expresarlo en términos de Paul Ricoeur, las historias dichas o narradas en las cartas son susceptibles de producir historias vividas, y éste es notoriamente el caso de la carta de Lorena, pero en mucho menor medida de la de Laura. En este contexto, cobra sentido lo que afirma Judith Butler, quien mantiene que la performatividad es una esfera en la que el poder actúa como discurso (cf. 2002). No obstante, y en vista de la realidad creada a partir del texto de Lorena en Morir en Berlín, se hace necesario invertir los términos de la afirmación de Butler tras constatar que es el discurso de resistencia de la exiliada el que actúa como poder que, dadas las consecuencias concretas detectables en el relato, desestabiliza los otros poderes actuantes en su entorno y crea una nueva realidad que no solamente interactúa con ella misma, sino con quienes la rodean o están en contacto mediato con ella. Tal es su fuerza perlocutiva y performativa, y este es un factor que marca una diferencia fundamental con la carta de Laura, cuya fuerza principal se circunscribe al ámbito ilocutivo, es decir, a la finalidad que persigue el acto de habla que constituye su texto: explicar, informar, recordar, pedir perdón, justificar(se), etc., pero sin operar performativamente en la destinataria o el entorno, dado que, como se sabe, ella opta finalmente por el facta, non verba y reemplaza la asepsia propia de la Filosofía del Derecho y de la escritura intransitiva -en tanto mera ilocución- por la activación del cuerpo inscripto por un trauma elidido y sublimado durante 20 años.

La carta de Laura es, last but not least, el punto de partida para la escritura de esa potencial historia circular que es la novela que finalmente leemos, una historia circular en tanto se inicia y concluye formalmente con las mismas palabras. En un Epílogo cuya primera frase parece dialogar con el inicio de Moby Dick: "Digamos que me llamo Mario" (459), el autor empírico parece recordar la lectura de las novelas de su maestro de Taller José Donoso, y utiliza el procedimiento de dar un giro sorpresivo a la perspectiva narrativa de la historia para 
reasignar, en el último capítulo, la autoría de la historia de Laura a su ex marido Mario, historia que éste reconstruye y/o ficcionaliza sobre la base de los papeles traídos por viento que llegan a sus manos y de su propia experiencia como personaje secundario en la historia de Laura. Este procedimiento de muda del narrador es el que había empleado José Donoso en su obra de exilio El jardín de al lado (1981), la misma novela que en Morir en Berlín lleva Lorena a su ex marido Mario en una de sus visitas a Berlín Oriental una vez expulsada de ese sector de la ciudad y del país. Por lo demás, la estructura global de El desierto recuerda asimismo la de otra novela de su maestro Donoso: en Este domingo (1966), una narración en cursiva y en primera persona de un narrador homointradiegético que rememora sucesos lejanos de la infancia alterna con la de un narrador hetero-intradiegético que complementa el conocimiento parcial del narrador-personaje, mostrando al lector el lado oculto y oscuro de la historia familiar inaccesible a la conciencia del narrador-personaje del texto en cursiva. Pero a diferencia de El desierto, en esta novela de Donoso al final no se produce la anagnórisis -literalmente, la revelación en el momento de la peripeteia de algo que estaba oculto- propia de la novela de Franz o, en clave Garcíamarquiana, la emergencia de un Melquíades o una Gloria Echeverría de Méndez, los verdaderos narradores de Cien años de soledad y de El jardín de al lado. En lo que concierne a Morir en Berlín y a los motivos de la culpa y el perdón que asociamos fugaz y acaso gratuitamente con Kafka, un final ad hoc para cerrar el doloroso capítulo-peregrinaje de la solicitud del Senador por una visa de regreso a su patria podría consistir en que, recordando el final que Kafka no alcanzó a escribir para el agrimensor K. de El castillo, pero sí comunicar oralmente a su amigo Max Brod, el Cónsul chileno en Berlín Occidental -envuelto en su fragancia a lavanda-, llegase al hospital con una carta para el Senador en el momento de su muerte, carta en la cual el terrible Padre castigador una vez más ratificaría a Don Carlos la prohibición de vivir en su país; no obstante, atendidas razones circunstanciales se le autorizaría para retornar provisionalmente a morir en Chile.

\section{REFERENCIAS}

Altamirano, Carlos y Beatriz Sarlo. 1997. Ensayos argentinos. De Sarmiento a la vanguardia. Buenos Aires: Ariel.

Bajtín, M.M. 1982. Estética de la creación verbal. México: Siglo XXI editores. Bajtín, M.M. 1989. Teoría y estética de la novela. Madrid: Taurus. 
Brito, Eugenia. 1994. Campos minados. Literatura post golpe en Chile. Santiago: Cuarto Propio.

Butler, Judith. 2002. Cuerpos que importan: Sobre los limites materiales y discursivos del sexo. Buenos Aires: Paidós.

Cerda, Carlos. 1993. Morir en Berlín. Santiago: Planeta.

Derrida, Jacques. 1975. La diseminación (Trad. José Martín Arancibia). Madrid: Fundamentos.

Donoso, José. 1966. Este domingo. Barcelona: Seix Barral.

Donoso, José. 1981. El jardín de al lado. Barcelona: Seix Barral.

Escandell Vidal, María Victoria. 1996. Introducción a la pragmática. Barcelona: Ariel.

Franz, Carlos. 2005. El desierto. Santiago: Sudamericana.

Huidobro, Vicente. 1976. Obras completas. Tomo I. Santiago: Andrés Bello. Jaspers, Karl. 1998. El problema de la culpa. Sobre la responsabilidad politica de Alemania. Barcelona: Paidós.

Lacroix, Jean. 1980. Filosofía de la culpabilidad. Barcelona: Editorial Herder.

Lewandowski, Theodor. 1982. Diccionario de lingüistica. Madrid: Cátedra.

Lotman, Yuri M. 1982. Estructura del texto artístico. Col. Fundamentos. Madrid: Ediciones Istmo.

Moulián Tomás. 1997. Chile actual. Anatomía de un mito. Santiago: Lom-Arcis.

Ricoeur, Paul. 1996. Tiempo y narración (3 vols.). México: Siglo XXI, vols. 2 y 3 .

Riera, Carme. 1996. "La epístola y la novela". En: Teoría de la novela. Antología de textos del siglo XX. (Enric Sullá ed.) Barcelona: Crítica, 2001.

Silesius, Angelus. 1949. Cherubinischer Wandersmann. München: Carl Hanser Verlag.

Vargas Llosa, Mario. 1968. "La novela", en Cuadernos de Literatura / 2 (s.l.). Fundación de Cultura Universitaria. 